\title{
Food-handling and feces reingestion in Ctenomys pearsoni (Rodentia, Ctenomyidae)
}

\author{
Carlos A. ALTUNA*, Leonardo D. BACIGALUPE and Sylvia CORTE
}

Altuna C. A., Bacigalupe L. D. and Corte S. 1998. Food-handling and feces reingestion in Ctenomys pearsoni (Rodentia, Ctenomyidae). Acta Theriologica 43: 433-437.

The food-handling and reingestive behaviour of feces by Ctenomys pearsoni Lessa and Langguth, 1983, was studied in the laboratory. All animals studied handle grasses with dexterity with one or both forepaws, and vigorously shaked it up and down before ingestion. Reingestion of feces occur frequently during resting periods and between feeding bouts. While performing both behaviours, C. pearsoni adopt a posture that not increase its height, what could be considered as and adaptation to the burrow space. Some convergences and divergences in the patterns of food-handling and reingestion of feces between Ctenomys and other subterranean rodents genera were remarked. We propose that the food-handling pattern is related to the cleaning of food; while the reingestion pattern might be related to water economy and to recover some particular nutrients.

Sección Etología, Facultad de Ciencias, Casilla de Correo 10773, 11400 Montevideo, Uruguay

Key words: Ctenomys, food-handling, coprophagy, rodents, Uruguay

\section{Introduction}

Optimal Foraging Theory has emphasized preingestional determinants of food profitability (eg resource abundance, handling and pursuit time) and practically ignored the postingestional mechanisms by which food is digested and absorbed (Bozinovic and Martínez del Río 1996).

As a general rule, nutrient quality of food is more important to herbivores than to carnivores and insectivores; because plants often lack essential components and so, a balanced intake must be preceded by a careful selection of plants and specific parts of plants species. Furthermore, preingestional mechanisms may evolve to maximize quality of food intake, while postingestional mechanisms to maximize the digestive and assimilative processes (Bozinovic 1995).

Herbivores fall into two groups, depending on where gut microbial fermentation takes place: foregut fermenters (ruminants and some marsupials), and hindgut or

\footnotetext{
*Present address: Sección Etología, Facultad de Ciencias, Calle Iguá s/n. 11400 Montevideo. Uruguay, fax: (5982) 5258617, e-mail: caltuna@genetica.edu.uy
} 
caecum fermenters as lagomorphs and herbivorous rodents (Foley and Cork 1992). Usually caecum fermenters practise autocoprophagy (Kenagy and Hoyt 1980).

Ctenomys is a subterranean rodent genus, strictly herbivore, distributed in southern South America between 17 and $54 \mathrm{~S}$ latitude (Reig et al. 1990). Ctenomys pearsoni Lessa and Langguth, 1983, inhabits southern Departments of Uruguay, develops mostly of its activities within its burrow systems, emerging only briefly to search for food (Altuna 1983, Altuna et al. 1991). The subterranean ecotope is relatively simple, stable and predictable (Nevo 1995). Because of its poor productivity and carrying capacity, subterranean rodents typically exhibit a generalist feeding strategy (Nevo 1995, B. Tassino, L. Bacigalupe and A. Chiesa, unpubl.). Since C. pearsoni is feeding on poor dietary items in the field, we predict an efficient behavior of food-handling and also feces reingestion. Both behaviors may attempt to maximize food processing rate allowing food cleaning and a positive water/nutrients balance respectively. Consequently, to understand the patterns of food use in this species, we conducted observations of the feeding behavior in individuals under laboratory conditions.

\section{Material and methods}

Observations were carried out on 61 adults specimens of $C$. pearsoni. Animals were live-trapped with Oneida Victor \# 0 traps in the following locations of southern Uruguay: Playa Penino, Departamento de San José ( $\left.34^{\circ} 68^{\prime} \mathrm{S}, 56^{\circ} 25^{\prime} \mathrm{W}\right),(n=20)$; Parque Roosevelt, Departamento de Canelones $\left(34^{\circ} 52^{\prime} \mathrm{S}, 56^{\circ} 04^{\prime} \mathrm{W}\right),(n=13)$; and Balneario Solís, Departamento de Maldonado ( $\left.34^{\circ} 47^{\prime} \mathrm{S}, 55^{\circ} 23^{\prime} \mathrm{W}\right)$, $(n=28)$. Animals were kept in captivity in individual all-glass terraria filled with sandy soil and fed ad libitum with carrots, potatoes and grasses. Individual observations and videotape records of the food-handling, ingestion and reingestion of feces patterns were carried out in front glass terraria; where animals were provided with grasses and forbs, which were collected in C. pearsoni's habitat. Observations were conducted randomly with respect to feeding times.

\section{Results and discussion}

Generally, when handling a food item, rodents use their forefeet, which seems to be an innate pattern (Vaughan 1988). Nevertheless many rodents with particular habits have reduced or lost their ability of prehension and food-handling, which can be seen in some cursorial and arboreal species (Vaughan 1988). In the same way, it would be expected that fossorial rodents, mainly those that have developed the scratch-digging modality have reduced their dexterity to handle because of structural and functional modifications of the forefeet (Ubila and Altuna 1990). In contrast to other Ctenomys species, C. pearsoni does not feed aboveground (Altuna 1983). During its brief aboveground foraging periods, it cuts grasses and forbs at soil level, and takes them into its burrow by walking or running backwards. During its backward travel, the tail acts as a probe like in other subterranean genera (Vaughan 1988). In the laboratory, when handling a 
food item, tuco-tucos, squat on their haunches without raising the head; this posture increments the height very little and we considered it to be an adaptation to burrow space. Grasses were grasped and shaked up and down with one or both forepaws. Stems, leaves and rhizomes were held between the three central digits and the thenar pad, which is extremely enlarged (Ubilla and Altuna 1990). Each sequence of shaking contains 4 to 18 movements performed at high velocity (mean $=0.16$ shakes/second, $n=69$ ). Large food items were handled with both forepaws, twisted and cut in small morsels with the incisors. These quick vibrations seem to be a stereotyped pattern because they are performed indiscriminately with dry, wet and dirty grasses. These results are in agreement with those reported by Vaughan (1966), for the pocket gopher Geomys bursarius. Both food-shaking or brushing food behaviour has been noticed for the African bathyergids Cryptomys damarensis (Bennet 1990) and Heterocephalus glaber (Lacey et al. 1991). Studies of stomach content in C. pearsoni (C. A. Altuna, unpubl.), indicate that only a little amount of soil is ingested, showing the effectiveness of food cleaning. Similar results were found in Geomys bursarius (Vaughan 1966). Tuco-tucos chew food items with propalinar and oblique masticatory movements; this combined power stroke produces an increase in the area of the plant tissues neccesary for break down the cell wall of plants.

Reingestion of feces is widespread among rodents, especially in those strictly herbivorous species (Kenagy and Hoyt 1980). Extensive studies in the laboratory carried out by Tálice et al. (1959), have noted the lack of coprophagy in captive tuco-tucos from Uruguay. However, our observations confirm that feces reingestion is a very frequent activity in $C$. pearsoni during resting periods and between feeding bouts. An animal takes fecal pellets with its lips and incisors without using its forepaws. To do this, its adopts a special posture, sitting on its hindquarters, bends the head to the anus and simultaneously moves the sacral region to the mouth, which enables it to take fecal pellets with the incisors. The bodys weight is bored by the tail and forelegs, while forepaws can be rested on the flanks or used to help balance the body. Fecal pellets are alternately chewed with oblique masticatory movements before swallowing, which is a qualitative difference from lagomorphs, which do not chew their fecal pellets.

The reingestion of feces in subterranean rodents has been described for Geomyidae (Kenagy and Hoyt 1980) and Bathyergidae (Bennet 1990, Lacey et al. 1991), however Bennett (1990) emphasized the lack of information about some genera like Spalax and Ctenomys. Some differences in the pattern of feces reingestion between these genera are evident, e.g. Geomys uses its forepaws to manipulate feces before chewing, whereas $C$. pearsoni and the bathyergids Cryptomys and Heterocephalus take the pellets directly with their incisors. As an herbivorous rodent, microbial fermentation of cellulose and pectins in C. pearsoni takes place in the caecum, which occupes the whole breadth of the abdominal cavity and weighs about $30 \%$ of the total animal weight (pers. obs.), and is the most developed caecum of any hystricognath rodent (Reig et al. 1990). Reingestion 
allows the passage of food through the intestinal tract a second time and permits a more complete digestion. We suggest that the adaptive value of this behaviour is related to these: (a) improve assimilation of nutrients, including recover some particular ones such as B and $\mathrm{K}$ vitamins, and aminoacids synthetized at the terminal part of the digestive tract as described by Kenagy and Hoyt (1980), and (b) retention of water, which is important given that C. pearsoni does not drink free water (Altuna 1991).

Recent papers (Bozinovic 1995, Bozinovic and Martínez del Río 1996) emphasized the role of physiological processes of diet selection. We suggests that behavioural mechanisms like food-handling and feces reingestion are also relevant for subterranean rodents because they maximize the food intake in order to obtain a higher efficiency in the use of water, energy and nutrients as an adaptation to the poorly subterranean ecotope. Further studies should focus to quantitative analysis of these behavioural patterns, as well as the daily rhythmicity of feces reingestion.

Acknowledgements: We wish to thank the field and laboratory cooperation of ours colleagues of the Sección Etología. B. Tassino, A. C. Silva and R. Vaz-Ferreira, to two anonymus referees for valuable criticism of a first draft of the manuscript. Specially thanks to F. Bozinovic for critical comments, discussions and friendship. This work was partially funded by a CSIC grant-in-aid for research to CAA.

\section{References}

Altuna C. A. 1983. Sobre la estructura de las construcciones de Ctenomys pearsoni Lessa \& Langguth, 1983 (Rodentia, Octodontidae). Comunicaciones Jornadas Ciencias Naturales, Montevideo 3: $70-72$.

Altuna C. A. 1991. Microclima de cuevas y comportamientos de homeostasis en una población del grupo Ctenomys pearsoni del Uruguay (Rodentia, Octodontidae). Boletin Sociedad Zoologica del Uruguay 6: $35-46$.

Altuna C. A., Francescoli G. and Izquierdo G. 1991. Copulatory pattern of Ctenomys pearsoni (Rodentia: Octodontidae) from Balneario Solís, Uruguay. Mammalia 55: 316-318.

Bennett N. C. 1990. Behaviour and social organization in a colony of the Damaraland mole-rat Cryptomys damarensis. Journal of Zoology, London 220: 225-248.

Bozinovic F. 1995. Nutritional energetics and digestive responses of an herbivorous rodent (Octodon degus) to different levels of dietary fiber. Journal of Mammalogy 76: 627-637.

Bozinovic F. and Martínez del Río C. 1996. Animals eat what they should not: why do they reject our foraging models? Revista Chilena de Historia Natural 69: 15-20.

Foley W. J. and Cork S. J. 1992. Use of fibrous diets by small herbivores: how far can the rules be bent? Trends in Ecology and Evolution 7: 159-162.

Kenagy G. J. and Hoyt D. F. 1980. Reingestion of feces in rodents and its daily rhythmicity. Oecologia (Berl.) 44: 403-409.

Lacey E. A., Alexander R. D., Braude, S. H., Sherman P. W. and Jarvis J. U. M. 1991. An ethogram for the nacked mole-rat: nonvocal behaviors. [In: The Biology of the nacked mole-rat. P. W. Sherman, J. U. M Jarvis and R. D. Alexander, eds]. Princeton University Press, New Jersey: 209-242.

Nevo E. 1995. Mammalian evolution underground. The ecology-genetic-phenetic interfaces. Acta Theriologica, Suppl. 3: 9-31. 
Reig O. A., Busch C., Ortells M. O. and Contreras J. R. 1990. An overview of evolution, systematics, population biology, cytogenetics, molecular biology and speciation in Ctenomys. [In: Evolution of Subterranean Mammals at the Organismal and Molecular Levels. E. Nevo and O. A. Reig, eds]. Alan R. Liss, Inc., New York: 71-96.

Tálice R. V., Momigliano-Tedeschi E., Laffitte de Mosera S. and Lagomarsino J. C. 1959. Investigaciones sobre Ctenomys torquatus, un roedor autóctono del Uruguay. Anales de la Facultad de Medicina, Montevideo 44: 452-462.

Ubilla M. and Altuna C. A. 1990. Analyse de la morphologie de la main chez des espces de Ctenomys de l'Uruguay (Rodentia, Octodontidae). Adaptations au fouissage et implications évolutives. Mammalia 34: 107-117.

Vaughan T. A. 1966. Food- handling and grooming behaviors in the plains pocket gopher. Journal of Mammology 47: 132-133.

Vaughan T. A. 1988. Mamíferos. Interamericana, México: 1-587.

Received 1 September 1997, accepted 10 March 1998. 